\title{
BMJ Open Passive enhanced safety surveillance of GSK's quadrivalent seasonal influenza vaccine in Belgium, Germany and Spain, an observational study: protocol for the 2018/2019 influenza season
}

Gaël Dos Santos, ${ }^{1}$ Anne Yeakey, ${ }^{2}$ Vishvesh Shende, ${ }^{3}$ Katie Smith, ${ }^{4}$ Frederic Lin, ${ }^{5}$ Elvira Zandman-van-Dijk, ${ }^{6}$ Silvia Damaso, ${ }^{7}$ Alexander Schmidt ${ }^{8}$

To cite: Dos Santos G, Yeakey A, Shende V, et al. Passive enhanced safety surveillance of GSK's quadrivalent seasonal influenza vaccine in Belgium, Germany and Spain, an observational study: protocol for the $2018 / 2019$ influenza season. BMJ Open 2019;9:e028043. doi:10.1136/ bmjopen-2018-028043

- Prepublication history and additional material for this paper are available online. To view these files, please visit the journal online (http://dx. doi org/10.1136/bmjopen-2018028043).

Received 19 November 2018 Revised 10 July 2019 Accepted 11 July 2019
Check for updates

(C) Author(s) (or their employer(s)) 2019. Re-use permitted under CC BY-NC. No commercial re-use. See rights and permissions. Published by BMJ.

For numbered affiliations see end of article.

Correspondence to Dr Gaël Dos Santos; gael.x.dos-santos@gsk.com

\section{ABSTRACT}

Introduction The European Medicines Agency requires Marketing Authorisation Holders providing seasonal influenza vaccines in Europe to conduct enhanced safety surveillance accounting for the different age groups based on the vaccine indication, in order to detect any potential increase of local and systemic adverse reactions early in an influenza season. To comply with this requirement, a multicountry European passive enhanced safety surveillance study has been set up to capture and assess adverse events occurring within 7 days following seasonal influenza vaccination. Here we share our surveillance protocol for the 2018/2019 influenza season.

Methods Nine healthcare professionals (HCPs) in Belgium, Germany and Spain have been recruited for this study. Cumulatively, approximately 1000 vaccinees will be provided with customised adverse event recording cards to report adverse events experienced within 7 days following vaccination with GSK's split-virion inactivated quadrivalent influenza vaccine. The cards are to be returned to the HCPs and the events encoded using an electronic case report form. Adverse event reporting rates will be analysed weekly and cumulatively, throughout the study period. Event rates will be described by country, age group and by influenza morbidity/mortality risk status of vaccinees (based on HCP assessment).

Ethics and dissemination Ethics committee approval was obtained for all participating sites prior to enrolment of the study participants. At the end of the study, each participating site will receive their data, and the outputs from the research will be made available to regulatory authorities. We intend to seek publication in peer-reviewed journals. GSK has posted a summary of the study protocol before the start of the study and results will be posted within 12 months of statistical analysis completion, in line with the National Institutes of Health recommendations. Trial registration number NCT03688620.

\section{INTRODUCTION}

Influenza is a major public health burden with estimates of 290000-650000 respiratory deaths resulting globally each year from seasonal influenza outbreaks and epidemics. ${ }^{1}$
Strengths and limitations of this study

- Three countries with different vaccination practices are included to enrol all age groups indicated for GSK's inactivated quadrivalent influenza vaccine and to account for diversity in terms of population characteristics.

- An electronic application is used to collect information in a standardised manner to facilitate the data extraction, cleaning and analysis; the aim being to maximise near real-time assessment.

- The sample size does not allow for the assessment of rare adverse events and other designs might be more appropriate for capturing such adverse events.

- Considering the passive nature of the setting, we cannot exclude under-reporting and potentially non-response bias, although this is expected to be limited with the visits scheduled.

- The age discrepancy between countries might result in different patterns of reporting.

Seasonal influenza causes 4-50 million symptomatic cases in the European Union (EU)/ European Economic Area annually and between 15000 and 70000 European citizens die every year of causes associated with influenza. ${ }^{2}$ Figures vary from season to season and according to the research methodology used. ${ }^{3}$ Annual vaccination is the most effective measure to reduce the risk of influenza infection and its complications. ${ }^{4}$ However, due to frequent genetic and antigenic changes in influenza viruses, seasonal vaccines are frequently reformulated with updated viral strains based on annual WHO recommendations. ${ }^{5}$ Therefore, there is a need for constant benefit-risk monitoring of these vaccines.

In the context of pharmacovigilance and continuous monitoring, the European Medicines Agency (EMA) released guidance on enhanced safety surveillance (ESS) for 
seasonal influenza vaccines in the $\mathrm{EU}^{6}$ and thus replaced the request on the small-scale clinical trials for the evaluation of safety and immunogenicity of seasonal influenza vaccines required up to $2015 .{ }^{7}$ The guidance sets out standards for surveillance that all Marketing Authorisation Holders (MAHs) of vaccines in the EU must address. The key objective of the EMA ESS is to rapidly detect any significant increase in the frequency and/or severity of expected reactions (local, systemic or allergic reactions) that could indicate a potential safety concern requiring further investigation. From the EMA guidance we can read that 'it is not expected that the enhanced surveillance can exclude a change in reactogenicity or detect signals of rare events and therefore, as with any other medicine, the routine pharmacovigilance processes should be continued throughout the life-cycle of the product to ensure detection of any new, unexpected or rare risks'. ${ }^{6}$ A recent review has discussed how several tools and routine surveillance activities could be used in addition to the ESS initiative to fulfil surveillance objectives. ${ }^{8}$

To implement the guidance appropriately, MAHs must first understand where their product(s) are to be distributed and administered (location/volume) and appreciate the disparities linked to local recommendations which may impact the subject population ultimately vaccinated. Specifically, for GSK's split-virion inactivated quadrivalent influenza vaccine (IIV4) 2018/2019 northern hemisphere influenza season, a feasibility assessment was conducted to identify which countries should be included in order to provide sufficient data (approximately 1000 vaccinees) with the objective to cover all age groups as per the GSK vaccine indications. The countries identified as suitable to host the study were: Belgium, Germany, and Spain where AlphaRix Tetra, Influsplit Tetra and Fluarix Tetra vaccines (three different trade names corresponding all to the GSK's IIV4) are distributed, respectively.

As opposed to active surveillance, no reminder or active follow-up of non-respondent subjects is performed. Subjects will be receiving their vaccination as per routine care prior to enrolment in the study. This passive ESS study is non-interventional and is designed to collect the appropriate safety information with the intent to capture in near real-time adverse events (AEs) experienced by vaccinees, in order to estimate the reporting rate of adverse events of interest (AEIs) experienced within 7 days following vaccination. To reach this objective customised $\mathrm{AE}$ reporting cards (AERCs) are to be completed by vaccinees or their parents/guardians after the receipt of their influenza vaccination. The cards are printed with predefined categories of AEIs to gather the most likely events to occur; along with an extra field to report any $\mathrm{AE}$ experienced that is not already listed as an AEI. Subsequent systematic coding of the information received by the vaccinees' healthcare practitioners is performed to standardise the data collection and analysis of AEIs.

This study protocol builds on the experience gained from other European passive ESS studies for seasonal influenza vaccines. ${ }^{9-16}$ MAHs have experimented with a number of different methodologies depending on the countries where their products are distributed. Their aim is to find the right balance between the need to select countries implementing early vaccination campaigns (to rapidly detect any safety issues following introduction of a new vaccine formulation) and the need to enrol all age groups as per vaccine indication. Vaccine recommendations differ from country to country and some countries are well equipped for electronic database research with links between several sources of information enabling studies of large numbers of patients. For example, in England with many general practices using Electronic Health Records (EHRs), GSK gathered information of AEIs from EHRs in addition to enhancing reporting through the use of AERCs. ${ }^{11} 1617$ However, nasal live attenuated influenza vaccine is preferentially recommended for children in England, ${ }^{18}$ and, although data were collected speedily, it was not possible to enrol a sufficient number of children to evaluate GSK's IIV4. The age representation was also a challenge encountered in a study conducted in Finland and the UK by another group, where vaccinees reported suspected adverse reactions via a telephone line with structured interview. ${ }^{13}$ This initiative was followed by a similar study in Ireland and the UK with an attempt to address the age group representation challenge. ${ }^{14}$

To date, there is no gold standard protocol for passive ESS. Certain methodologies may be better suited to specific countries and the countries recruited depend on where vaccine is used with sufficient market share to enable rapid collection of the required safety data. In conclusion, the study described in the reported protocol is intended to provide the necessary pharmacovigilance data as per requirement from the EMA guidance. Additionally, we anticipate that this study design and subsequent results may help inform decisions regarding future seasonal influenza vaccine safety surveillance studies in Europe.

\section{METHODS AND ANALYSIS}

\section{Study setting and population}

This prospective passive ESS study is anticipated to run from 1 October 2018 to 15 January 2019, with subject recruitment planned between 1 October 2018 and 31 December 2018 for subjects requiring one dose of vaccine. For subjects requiring two doses (namely those under 9 years of age who have not been previously vaccinated against influenza and therefore require two doses administered 4 weeks apart), the recruitment will stop at 1 December 2018 to allow sufficient time for follow-up. Nine healthcare professionals (HCPs) across Belgium, Germany and Spain will recruit approximately 1000 subjects. Due to feasibility constraints, Belgium and Germany, where vaccine coverage in children is low, will only recruit subjects 18 years of age and above (with German participating sites targeting subjects aged from 50 years onwards). Spain will target subjects between 6 months and 65 years of age at the time of the vaccination. 
Written informed consent/informed assent will be collected as part of the study procedures subsequent to subjects receiving GSK's IIV4 according to the local guidelines $^{20}$ (see online supplementary file). Children in care will be excluded from the study (defined as children under the control or protection of an agency, organisation, institution or entity by the courts, the government or a government body, acting in accordance with powers conferred on them by law or regulation).

\section{Sample size considerations}

The table 1 shows the probability to observe at least one $\mathrm{AE}$, the exact $95 \% \mathrm{CIs}^{21}$ for the percentage of vaccinated subjects with the $\mathrm{AE}$ and relative SEs (RSEs) for a range of scenarios in terms of number of vaccinated subjects and true percentage of vaccinated subjects with the $\mathrm{AE}$. Of note, a SE measure indicates the extent to which estimates derived from sample population surveys are likely to differ from data that would have been obtained from the overall population and is expressed as a number. The RSE is the SE divided by the estimate, usually expressed as a percentage. The larger the RSE, the less precise the survey estimate is of the true value in the population (estimates greater than 25\%-30\% should be used with caution). ${ }^{22}{ }^{23}$ With an overall sample size of 1000 vaccinated subjects expected to be achieved by the end of the study period and a true percentage of vaccinated subjects with the $\mathrm{AE}$ ranging from $1 \%$ to $10 \%$, the corresponding probability to observe at least one vaccinated subject with the $\mathrm{AE}$ is $>99 \%$ and the RSE ranges from $9.5 \%$ to $31.5 \%$.

The table 2 shows the evolution by week of the cumulative probability to observe at least one $\mathrm{AE}$, the exact 95\% CI for the cumulative percentage of vaccinated subjects with the AE and RSE in the course of the study for an overall sample size of 1000 ((all countries) and 333 (by country)) vaccinated subjects and assuming an average percentage of vaccinated subjects experiencing an $\mathrm{AE}$ of $1 \%$. The aim of computing these probabilities is to estimate what $\mathrm{AE}$ can be detected in the study with the study sample size. With a sample size of 1000 subjects, the study could detect very common $(\geq 10 \%)$, common $(\geq 1 \%$ to $<10 \%)$ and uncommon $(\geq 0.1 \%$ to $<1 \%)$ AEIs and other AEs.

\section{Data collection and analysis}

Before the start of the study, participating HCPs will receive induction training to acquire certification that allows access to the application that will be used to encode the subjects' information. HCPs will then provide each vaccinee or their parent/guardian with a customised AERC (see figure 1) for the recording of any AE in the 7 days following the first and second vaccination (if appropriate). The cards will contain predefined AEIs to be reported as well as a free text field to report any other AEs experienced by the subjects. Subjects will also have the possibility to indicate that no $\mathrm{AE}$ occurred within the 7 days' time window. The subjects are to return the cards to the HCP, and practice staff will enter the information in an electronic case report form (eCRF). The AEIs are to be entered according to the code list provided to each practice (see figure 2), in which AEIs are coded according to the Medical Dictionary for Regulatory Activities (MedDRA) classification ${ }^{24}$ and the International Statistical Classification of Diseases and Related Health Problems 10th revision (ICD-10). ${ }^{25}$

The table 3 provides the detailed schema for study procedures and completion of the eCRFs at the corresponding study visits. The procedures include, informed consent, collection of basic demography data ( (month and year of birth (year only in Germany), geographic ancestry (Black or African American, Asian-central/ south Asian heritage, Asian-east Asian heritage, Asiansouth east Asian heritage, White-Arabic/north African heritage, White-Caucasian/European heritage, other), gender) and information on the vaccination-namely date of vaccination, batch number and any vaccine co-administrations. Investigators are also required to record, according to their experience and judgement, the 'risk status' of the vaccinee-either at risk or not at an elevated risk for influenza related morbidity and mortality. Some guidance was provided based on the risk groups usually recommended for vaccination in the EU. These usually encompass but are not limited to: pregnant women in some countries; children 6-59 months; individuals over 6 months with chronic heart or lung disease, metabolic or renal disease, chronic liver disease, chronic neurological conditions or immunodeficiencies; residents of long-term care facilities for older or disabled persons; healthcare workers including those who work in facilities that care for the elderly or those with disabilities. The risk status is collected to account for potential differences in healthcare seeking behaviours that could impact the probability of reporting any $\mathrm{AE}$ experienced.

The primary objective of the study is to estimate, in each country and overall, the cumulative percentages of subjects reporting AEIs and/or other AEs, using AERCs, within 7 days following vaccination with GSK's IIV4. For each vaccine dose (note that a second dose of GSK's IIV4 is planned to be administered only to children aged $<9$ years who have not previously been vaccinated against influenza in preceding seasons), the cumulative percentages of subjects reporting AEIs and/or other AEs within 7 days postvaccination period (ie, the day of vaccination and the following 6 days) using AERCs from study start up to each study week (International Standardisation Organisation weeks 40-52) will be estimated by MedDRA preferred term, overall and by country; the denominator being the number of subjects vaccinated with GSK's IIV4 (and provided with an AERC) at any point from study start (ie, 1 October 2018) up to the end of the week of interest, in each country or for all countries and the numerator being the number of subjects from the denominator who reported the $\mathrm{AE}$ on the AERC within 7 days following vaccination. The $95 \%$ CI will be computed on all estimated percentages.

The secondary objectives are to estimate, in each country and overall, the weekly percentages of subjects reporting 


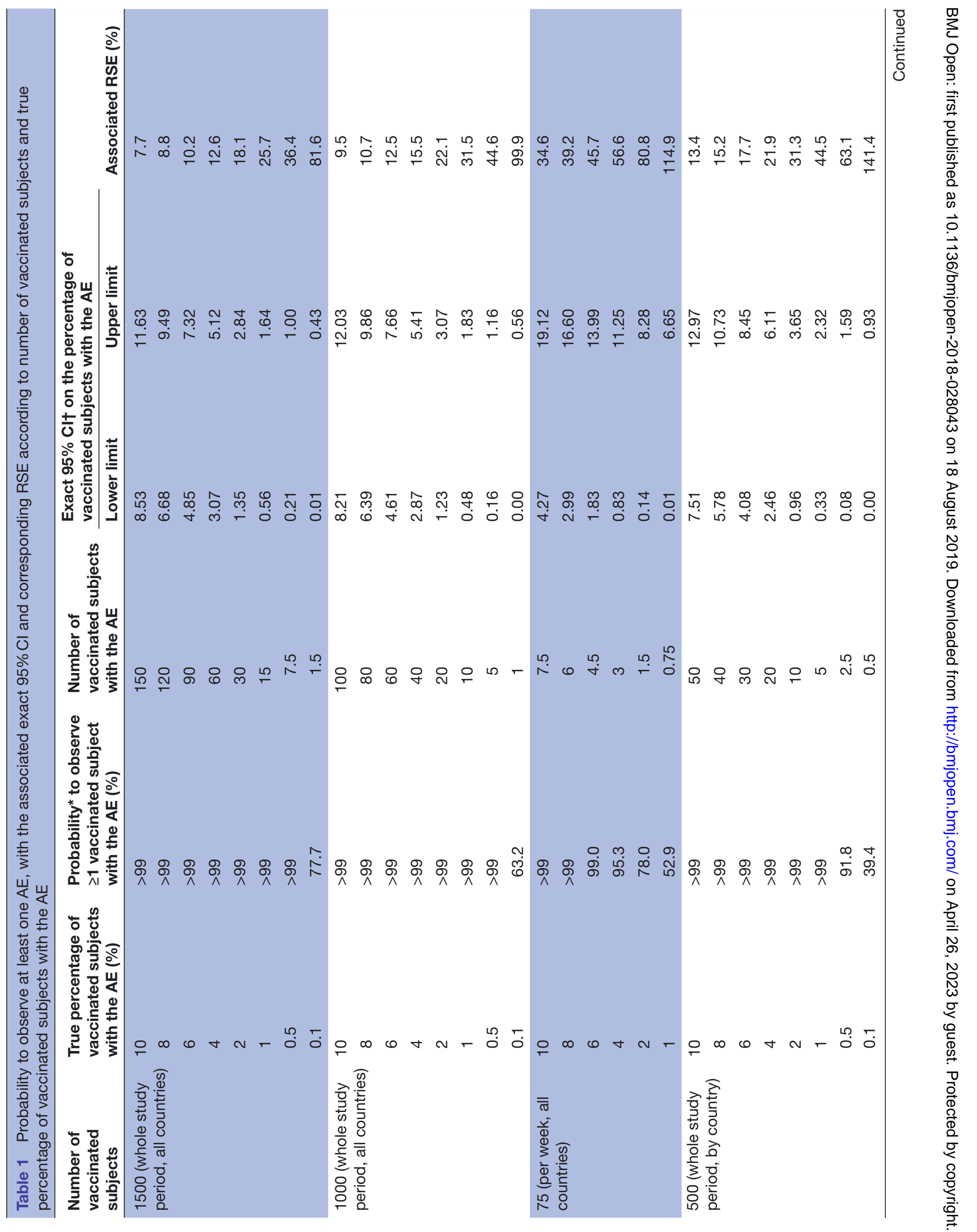




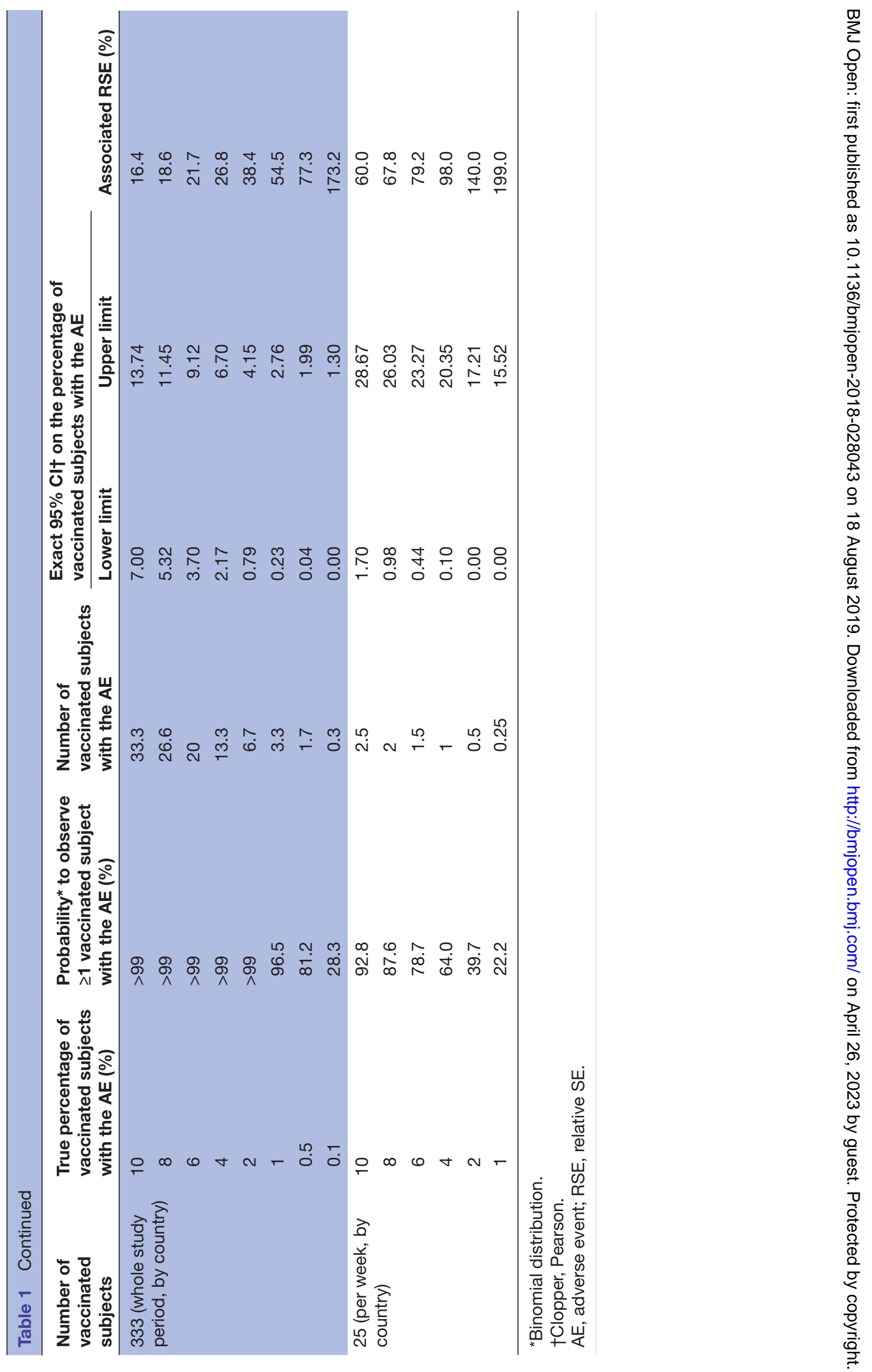




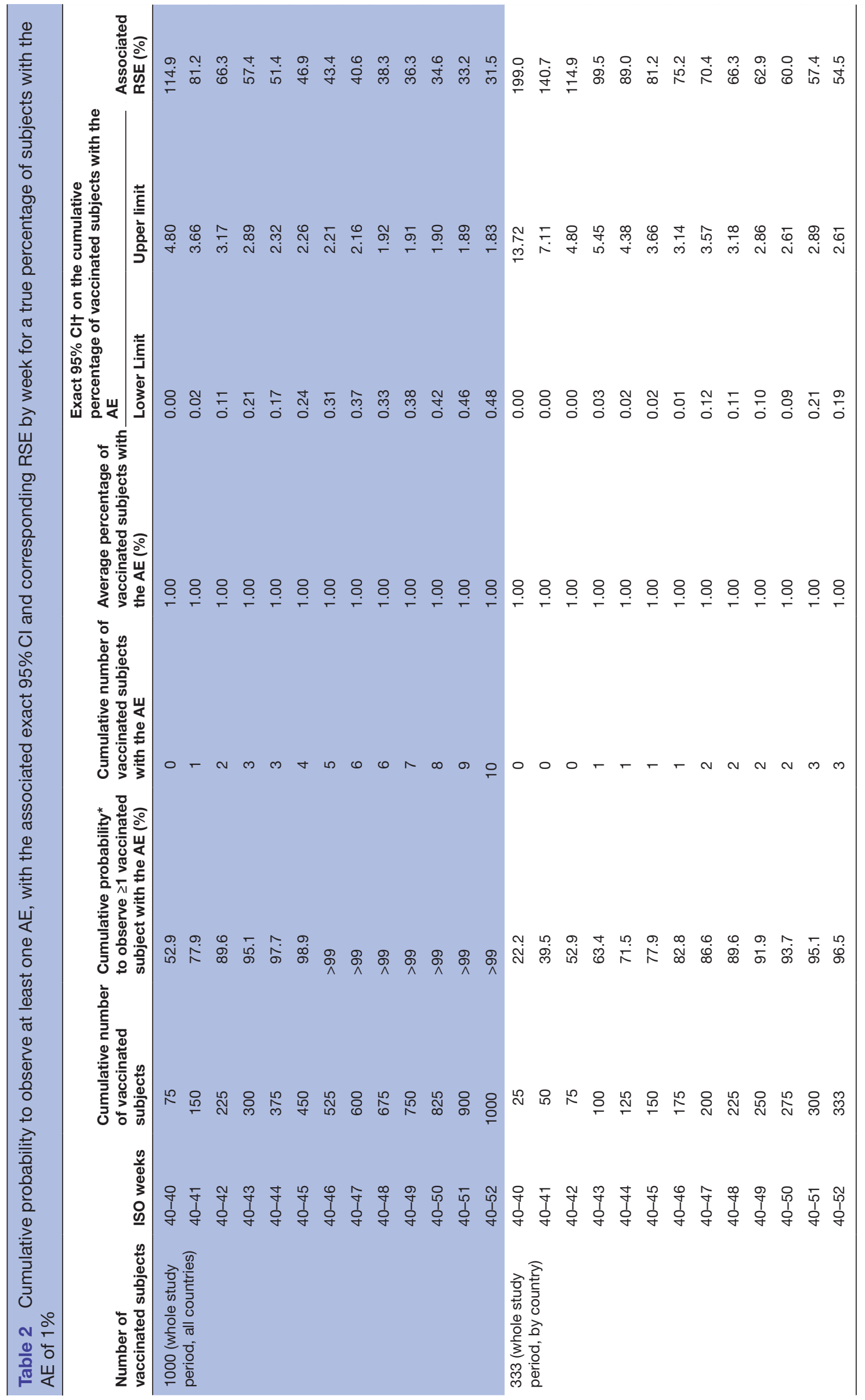



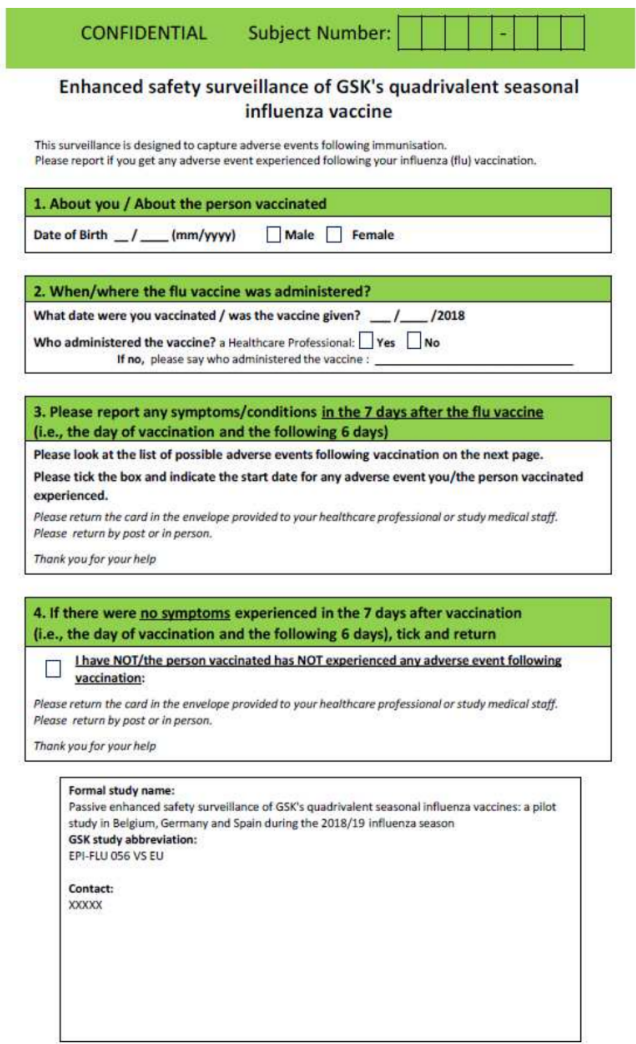

Figure 1 Adverse event reporting card.

AEIs and/or other AEs using AERCs, within 7 days following vaccination with GSK's IIV4 overall, by age strata (6 months to 17 years; $18-65$ years; $>65$ years) and risk status (at risk/ not at risk) and the cumulative percentages (as detailed above) by age strata and risk status.

\section{Data management procedure}

A validated GSK-defined electronic data base application will be used to collect the data. Subject initials will not be collected or transmitted to GSK. Relevant data necessary for analysis and reporting will be entered/transmitted into a validated and secured database or data system using an audit trail system. Clinical data management will be performed in accordance with applicable GSK standards and data cleaning procedures. GSK standards are based on the Clinical Data Interchange Standards Consortium. ${ }^{26}$ While completed eCRFs are reviewed by GSK site monitors using a risk-based monitoring approach, ${ }^{27}$ omissions or inconsistencies detected by subsequent eCRF review may necessitate clarification or correction of omissions or inconsistencies with documentation and approval by the investigator or appropriately qualified member of site staff.

\section{Routine pharmacovigilance procedures and safety reporting}

The routine reporting of AEs/serious adverse events (SAEs) to regulatory bodies according to local routine practices will continue throughout the study period. Although the data collected for this study are primarily safety related, the reporting mechanisms for AEs/SAEs to regulatory authorities should not be altered and should continue according to

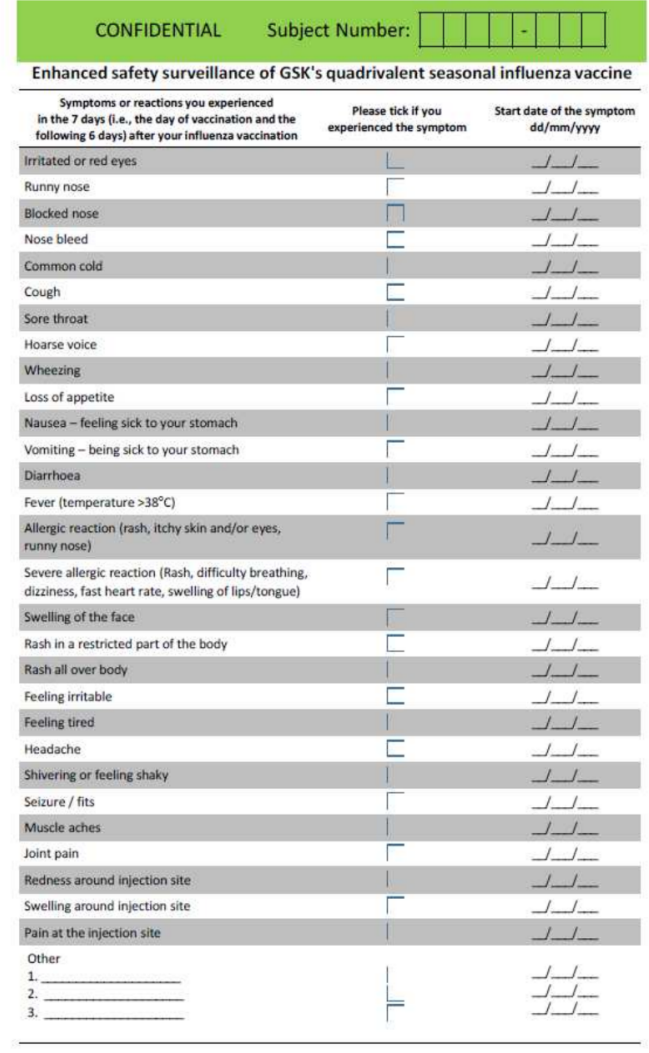

local standards. (SAEs considered related to the vaccine will be collected as part of the study using the eCRF.)

The investigator or site staff is/are responsible for the detection, documentation and reporting of events meeting the criteria and definition of an $\mathrm{AE}$ of specific interest or an SAE as provided in this protocol.

$\mathrm{An} \mathrm{AE}$ is any untoward medical occurrence in a subject, temporally associated with the use of a medicinal product, whether or not considered related to the medicinal product or temporally associated with a study procedure. ${ }^{28}$

A SAE is any untoward medical occurrence that:

a. Results in death.

b. Is life-threatening.

c. Requires hospitalisation or prolongation of an existing hospitalisation.

d. Results in disability/incapacity.

e. Is a congenital anomaly/birth defect in the offspring of a study subject.

If the participating HCP becomes aware of an SAE experienced by a study participant occurring within 7 days postvaccination that is deemed to be related to GSK's quadrivalent seasonal influenza vaccine according to the judgement of the HCP, the SAE should be reported to GSK within 24 hours of becoming aware using the eCRF.

Patient and public involvement

Patients or the public were not involved in the design of this study. 
Project title: Passive enhanced safety surveillance of GSK's quadrivalent seasonal influenza vaccines: a pilot study in Belgium, Germany and Spain during the 2018/19 influenza season Preferred code list

If a patient presents with adverse events within 7 days following vaccination (i.e., the day of vaccination and the following 6 days), please code (ideally as a symptom) any of the following events into their computerised record

\begin{tabular}{|c|c|c|c|c|c|c|c|}
\hline Pre-defined AEIs & $\begin{array}{l}\text { MedDRA } \\
\text { PT Terms }\end{array}$ & $\begin{array}{r}\text { ICD-10 } \\
\text { Codes }\end{array}$ & Notes & Pre-defined AEls & $\begin{array}{l}\text { MedDRA } \\
\text { PT Terms }\end{array}$ & $\begin{array}{l}\text { ICD-10 } \\
\text { Codes }\end{array}$ & Notes \\
\hline \multicolumn{4}{|c|}{ Respiratory/Miscellaneous } & \multicolumn{4}{|c|}{ General non-specific symptoms } \\
\hline Conjunctivitis & $\begin{array}{l}\text { Conjunctivitis } \\
\text { (10010741) }\end{array}$ & H10.9 & $\begin{array}{l}\text { Irritated or } \\
\text { red eyes }\end{array}$ & \multirow{3}{*}{ Irritability } & \multirow{3}{*}{$\begin{array}{l}\text { Irritability } \\
(10022998)\end{array}$} & \multirow{3}{*}{$\begin{array}{c}\text { R68.12 } \\
\text { (Fussy } \\
\text { baby) } \\
\text { R45.4 } \\
\text { (Irritability } \\
\text { and anger) }\end{array}$} & \multirow{3}{*}{$\begin{array}{l}\text { Feeling } \\
\text { irritable }\end{array}$} \\
\hline Rhinorrhoea & $\begin{array}{c}\text { Rhinorrhoea } \\
\text { (10039101) }\end{array}$ & J34.89 & Runny nose & & & & \\
\hline \multirow[t]{2}{*}{ Nasal congestion } & \multirow{2}{*}{$\begin{array}{c}\text { Nasal } \\
\text { congestion } \\
(10028735)\end{array}$} & \multirow[t]{2}{*}{ R09.81 } & \multirow[t]{2}{*}{ Blocked nose } & & & & \\
\hline & & & & \multirow{2}{*}{ Fatigue } & \multirow{2}{*}{$\begin{array}{c}\text { Fatigue } \\
\text { (10016256) }\end{array}$} & \multirow{2}{*}{\multicolumn{2}{|c|}{$\begin{array}{l}\text { Feeling } \\
\text { tired }\end{array}$}} \\
\hline \multirow{2}{*}{ Epistaxis } & \multirow{2}{*}{$\begin{array}{l}\text { Epistaxis } \\
\text { (10015090) }\end{array}$} & \multirow{2}{*}{ R04.0 } & \multirow{2}{*}{ Nose bleed } & & & & \\
\hline & & & & \multirow{2}{*}{ Headache } & \multirow{2}{*}{$\begin{array}{l}\text { Headache } \\
(10019211)\end{array}$} & \multirow{2}{*}{ R51 } & \multirow{2}{*}{ Headache } \\
\hline Coryza & $\begin{array}{c}\text { Rhinitis } \\
(10039083)\end{array}$ & J00 & Common cold & & & & \\
\hline Cough & $\begin{array}{l}\text { Cough } \\
\text { (10011224) }\end{array}$ & R05 & Cough & Bell's palsy & $\begin{array}{c}\text { Facial paralysis } \\
\text { (10016062) }\end{array}$ & G51.0 & \\
\hline \multirow{2}{*}{$\begin{array}{c}\text { Oropharyngeal } \\
\text { pain }\end{array}$} & \multirow{2}{*}{$\begin{array}{l}\text { Oropharyngeal } \\
\text { pain } \\
(10068319)\end{array}$} & \multirow[t]{2}{*}{ J02.9 } & \multirow[t]{2}{*}{ Sore throat } & Peripheral tremor & $\begin{array}{c}\text { Chills } \\
(10008531)\end{array}$ & R68.83 & $\begin{array}{c}\text { Shivering/ } \\
\text { chills }\end{array}$ \\
\hline & & & & & Guillain-Barré & & \\
\hline Hoarseness & $\begin{array}{c}\text { Dysphonia } \\
\text { (10013952) }\end{array}$ & R49.0 & Hoarse voice & $\begin{array}{l}\text { Guillain-Barre } \\
\text { Syndrome (GBS) }\end{array}$ & $\begin{array}{c}\text { syndrome } \\
(10018767)\end{array}$ & G61.0 & \\
\hline Wheezing & $\begin{array}{l}\text { Wheezing } \\
\text { (10047924) }\end{array}$ & R06.2 & Wheezing & Seizure/Febrile & $\begin{array}{l}\text { Febrile } \\
\text { convulsion }\end{array}$ & R56.0 & Seizure/ fits \\
\hline & Gastrointestin & & & & $(10016284)$ & & \\
\hline & Decreased & & & & Musculoskelet & & \\
\hline Decreased appetite & $\begin{array}{c}\text { appetite } \\
(10061428)\end{array}$ & R63.0 & $\begin{array}{l}\text { Loss of } \\
\text { appetite }\end{array}$ & $\begin{array}{c}\text { Muscle aches/ } \\
\text { Myalgia }\end{array}$ & $\begin{array}{c}\text { Myalgia } \\
(10028411)\end{array}$ & M79.1 & $\begin{array}{l}\text { Muscle } \\
\text { aches }\end{array}$ \\
\hline Nausea & $\begin{array}{c}\text { Nausea } \\
(10028813)\end{array}$ & R11.0 & Feeling sick & Arthropathy & $\begin{array}{l}\text { Arthropathy } \\
(10003285)\end{array}$ & $\begin{array}{l}\text { M25.9, } \\
\text { M19.9 }\end{array}$ & Joint pain \\
\hline Vomiting & Vomiting & R11.10 & Being sick & & Local Symptom & & \\
\hline & (10047700) & & & & Injection site & & Redness \\
\hline Diarrhoea & $\begin{array}{c}\text { Diarrhoea } \\
(10012735)\end{array}$ & R19.7 & Diarrhea & Local erythema & erythema & T50.B95 & $\begin{array}{c}\text { around the } \\
\text { injection }\end{array}$ \\
\hline & Fever/Pyrexia & & & & & & site \\
\hline Fever & $\begin{array}{c}\text { Pyrexia } \\
(10037660)\end{array}$ & R50.9 & $\begin{array}{c}\text { Temperature } \\
>38^{\circ} \mathrm{C}\end{array}$ & & Injection site & & $\begin{array}{l}\text { Swelling } \\
\text { around the }\end{array}$ \\
\hline & ensitivity/Anaph & ylaxis & & Local swelling & swelling & T50.B95 & injection \\
\hline Hypersensitivity & Hypersensitivity & T78.4 & All & & (10053425) & & site \\
\hline reaction & (10020751) & & reaction & & Injection site & & Pain at the \\
\hline $\begin{array}{l}\text { Anaphylactic } \\
\text { reaction }\end{array}$ & $\begin{array}{l}\text { Anaphylactic } \\
\text { reaction } \\
(10002198)\end{array}$ & T78.2 & $\begin{array}{l}\text { Severe allergic } \\
\text { reaction }\end{array}$ & Local pain & $\begin{array}{c}\text { pain } \\
(10022086)\end{array}$ & T50.B95 & $\begin{array}{l}\text { injection } \\
\text { site }\end{array}$ \\
\hline Facial oedema & $\begin{array}{c}\text { Face oedema } \\
(10016029)\end{array}$ & $\mathrm{R} 60.0$ & $\begin{array}{l}\text { Swelling of } \\
\text { the face }\end{array}$ & $\begin{array}{l}\text { If a patient hands } \\
\text { please cod }\end{array}$ & $\begin{array}{l}\text { back the AERC w } \\
\text { these and repor }\end{array}$ & $\begin{array}{l}\text { vith their syr } \\
r t \text { it in the ec }\end{array}$ & $\begin{array}{l}\text { mptoms - } \\
\text { CRF }\end{array}$ \\
\hline & Rash & & & & & & \\
\hline Rash & $\begin{array}{c}\text { Rash } \\
\text { (10037844) }\end{array}$ & L27.1 & $\begin{array}{c}\text { Rash in a } \\
\text { restricted part } \\
\text { of the body }\end{array}$ & $\begin{array}{l}\text { N.B.: In coding these } \\
\text { causation; this can o } \\
\text { Principal Investigato }\end{array}$ & $\begin{array}{l}\text { conditions there } \\
\text { hly come from ad } \\
\text { : XXXX }\end{array}$ & $\begin{array}{l}\text { is no assum } \\
\text { dvanced ana }\end{array}$ & $\begin{array}{l}\text { nption about } \\
\text { lytics. }\end{array}$ \\
\hline Generalised rash & $\begin{array}{c}\text { Rash } \\
\text { generalised } \\
(10037858)\end{array}$ & L27.0 & $\begin{array}{c}\text { Rash all over } \\
\text { body }\end{array}$ & & & & \\
\hline
\end{tabular}

Figure 2 Code list of prespecified AEls. AERC, adverse event reporting card; AEls, adverse events of interest; eCRF, electronic case report form; GBS, Guillain-Barré Syndrome; ICD-10, International Statistical Classification of Diseases and Related Health Problems 10th revision; MedDRA, Medical Dictionary for Regulatory Activities; PT, preferred term.

\section{Ethics and dissemination}

The following Ethics Committees (ECs), or Institutional Review Boards (IRBs) and Regional Authorities were consulted in line with country requirements, namely, Commissie Medische Ethiek UZ/KU Leuven (EC) in Belgium (S61698; approval received 24 August);
Ethik-Kommission der Bayerischen (EC) in Germany (18056; approval received 20 September) and in Spain the PEIBA (IRB and RA combined) for Andalusia (0031/18 EPA-SP; approval received 26 September) and Hospital Vall de Hebron (IRB) and Goli Gurina (RA) for Catalonia (ID-RTF-021; approval received 22 October). 


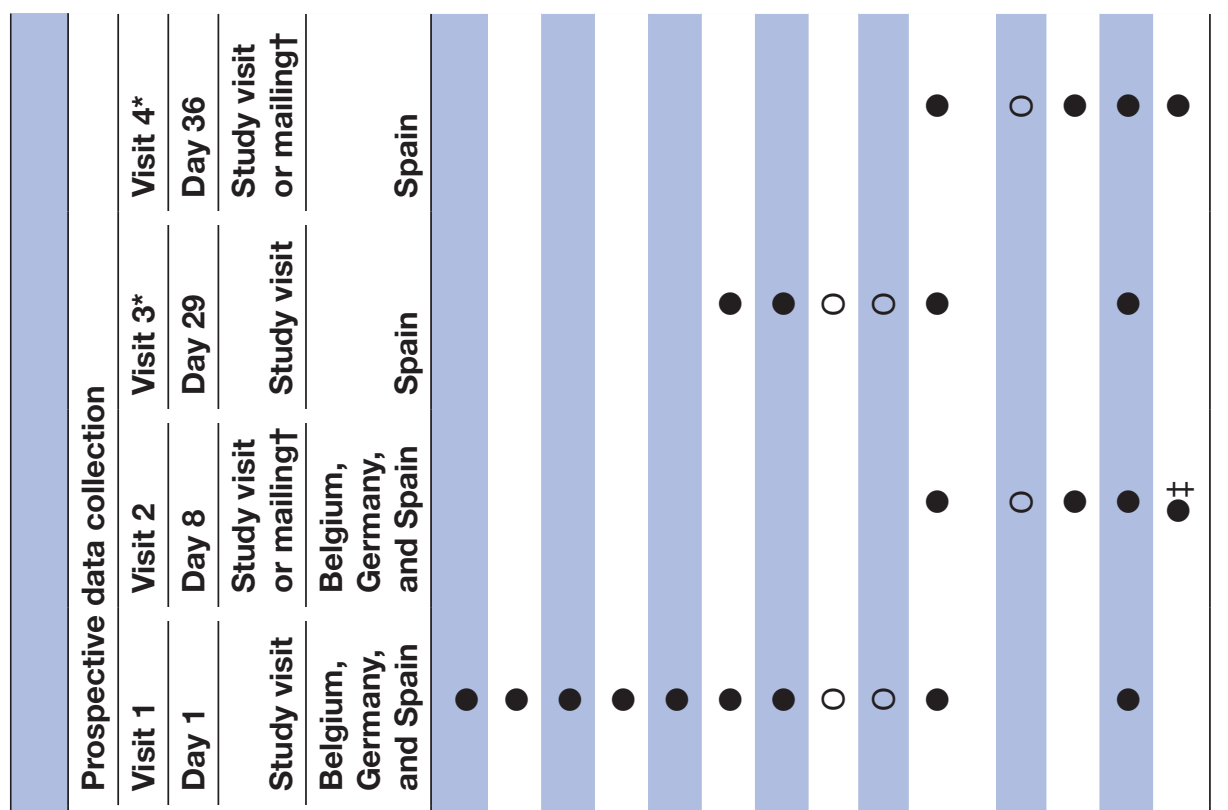


In the respective countries, the ethics approval preceded the study participant's enrolment, with the first subject enrolled at the earliest on 1 October 2018.

The outputs from the research will be disseminated primarily through peer reviewed journal articles and presented at relevant seminars and conferences. GSK will post the study protocol and the results summary within 12 months of statistical analysis completion (following review and comment by GSK) on GSK's Clinical Study Register (accessible at www.gsk-clinicalstudyregister.com, GSK Study ID 207737) and on the US National Library of Medicine website www.clinicaltrials.gov (NCT03688620). The study report will also be posted 30 days after the publication of the primary and main secondary endpoints. Additionally, at the end of the study, each participating site will receive their data.

\section{Trademarks}

AlphaRix Tetra, Influsplit Tetra and Fluarix Tetra are trademarks of the GSK group of companies.

\section{Author affiliations}

${ }^{1}$ Vaccine Research and Development Center Clinical R\&D Flu/RSV Combo, GSK, Wavre, Belgium

${ }^{2}$ Systems Management Group Pharma Safety, GSK, Rockville, Maryland, USA

${ }^{3}$ Clinical Safety and Pharmacovigilance, GSK, Wavre, Belgium

${ }^{4}$ Syneos Health (on behalf of GSK), Farnborough, UK

${ }^{5}$ Medical Writing, 4Clinics (on behalf of GSK), Waterloo, Belgium

${ }^{6}$ Data Science and Clinical Systems, Data management Vaccine Research and

Development Center, GSK, Amsterdam, The Netherlands

${ }^{7}$ Biostatistics Epidemiology, GSK, Wavre, Belgium

${ }^{8}$ Clinical R\&D, GSK, Rockville, Maryland, USA

Acknowledgements The authors thank Stéphanie Gilon and Jacqueline Miller from GSK for their contribution to this study. The authors also thank Business \& Decision Life Sciences platform for editorial assistance and manuscript coordination, on behalf of GSK. Rachel Emerson provided writing support and Bruno Dumont coordinated manuscript development and editorial support.

Contributors GDS led the development of the protocol and wrote the first draft of the manuscript. AY and VS provided critical contributions to safety sections. SD contributed to the statistical sections. EZ-v-D contributed to the data management section, KS for study operational aspects and FL coordinated the protocol writing. AS provided critical contributions to the clinical and epidemiology sections. All authors contributed to subsequent revisions and approved the final version.

Funding GlaxoSmithKline Biologicals SA is the funding source and is involved in all stages of the study (NCT03688620). GlaxoSmithKline Biologicals SA also funded all costs associated with the development and the publishing of the present manuscript. All authors had full access to the data and agreed with the submission of the publication. The authors received no financial support or other form of compensation related to the development of the manuscript.

Competing interests VS declares he is employed by VPN Consultancy Limited working on behalf of the GSK group of companies. KS declares she is employed by Syneos Health working on behalf of the GSK group of companies. FL declares he is employed by 4Clinics Belgium working on behalf of the GSK group of companies. AS reports he was employed by the GSK group of companies at the time of the study and reports he holds shares in the GSK group of companies. EZ-v-D declares she is employed by the GSK group of companies. AY, GDS and SD declare they are employed by the GSK group of companies and hold shares in the GSK group of companies.

\section{Patient consent for publication Not required.}

Provenance and peer review Not commissioned; externally peer reviewed.

Open access This is an open access article distributed in accordance with the Creative Commons Attribution Non Commercial (CC BY-NC 4.0) license, which permits others to distribute, remix, adapt, build upon this work non-commercially, and license their derivative works on different terms, provided the original work is properly cited, appropriate credit is given, any changes made indicated, and the use is non-commercial. See: http://creativecommons.org/licenses/by-nc/4.0/.

\section{REFERENCES}

1. World Health Organization. Fact sheets. influenza (seasonal). Available: https://www.who.int/news-room/fact-sheets/detail/ influenza-(seasonal) [Accessed Nov 2018].

2. Thoelen S, Van Damme P, Leentvaar-Kuypers A, et al. The first combined vaccine against hepatitis $A$ and $B$ : an overview. Vaccine 1999;17:1657-62.

3. Nicoll A, Ciancio BC, Lopez Chavarrias V, et al. Influenza-related deaths - available methods for estimating numbers and detecting patterns for seasonal and pandemic influenza in Europe. Euro Surveill 2012;17.

4. World Health Organization. Influenza. vaccines. Available: http:// www.who.int/influenza/vaccines/en/ [Accessed Oct 2018].

5. World Health Organization. Who recommendations on the composition of influenza virus vaccines. Available: https://www.who. int/influenza/vaccines/virus/recommendations/en/ [Accessed May 2019].

6. European Medicines Agency. Interim guidance on enhanced safety surveillance for seasonal influenza vaccines in the Eu (EMA/ PRAC/222346/2014), 2014. Available: https://www.ema.europa. eu/en/documents/scientific-guideline/interim-guidance-enhancedsafety-surveillance-seasonal-influenza-vaccines-eu_en.pdf [Accessed Dec 2018].

7. Wijnans L, Voordouw B. A review of the changes to the licensing of influenza vaccines in Europe. Influenza Other Respi Viruses 2016;10:2-8.

8. Dos Santos G. Challenges in implementing yearly enhanced safety surveillance of influenza vaccination in Europe: lessons learned and future perspectives. Hum Vaccin Immunother 2019;27:1-13.

9. Demeulemeester M, Lavis N, Balthazar Y, et al. Rapid safety assessment of a seasonal intradermal trivalent influenza vaccine. Hum Vaccin Immunother 2017;13:889-94.

10. McNaughton R, Lynn E, Osborne V, et al. Safety of intranasal quadrivalent live attenuated influenza vaccine (QLAIV) in children and adolescents: a pilot prospective cohort study in England. Drug Saf 2016;39:323-33.

11. de Lusignan S, Dos Santos G, Byford R, et al. Enhanced safety surveillance of seasonal quadrivalent influenza vaccines in English primary care: interim analysis. Adv Ther 2018;35:1199-214.

12. de Lusignan S, Dos Santos G, Correa A, et al. Post-authorisation passive enhanced safety surveillance of seasonal influenza vaccines: protocol of a pilot study in England. BMJ Open 2017;7:e015469.

13. Bricout $H$, Chabanon $A L$, Souverain $A$, et al. Passive enhanced safety surveillance for Vaxigrip and Intanza $15 \mu \mathrm{g}$ in the United Kingdom and Finland during the Northern hemisphere influenza season 2015/16. Euro Surveill 2017;22

14. Chabanon AL, Bricout $\mathrm{H}$, Ballandras $\mathrm{C}$, et al. Report from enhanced safety surveillance of two influenza vaccines (Vaxigrip and Intanza $15 \mu \mathrm{g}$ ) in two European countries during influenza season 2016/17 and comparison with $2015 / 16$ season. Hum Vaccin Immunother 2018;14:378-85.

15. Stuurman AL, Verstraeten T, De Schryver A. Rapid assessment of the reactogenicity of a 2016-2017 seasonal influenza vaccine: results from a feasibility study. Expert Rev Vaccines 2017;16:187-91.

16. de Lusignan S, Ferreira F, Damaso S, et al. Enhanced passive surveillance of influenza vaccination in England, 2016-2017- an observational study using an adverse events reporting card. Hum Vaccin Immunother 2019;15:1048-59.

17. de Lusignan S, Correa A, Dos Santos G, et al. Brand specific, near real time, enhanced safety surveillance of influenza vaccines in general practice winter 2015/16: feasibility study (Preprint). JMIR Public Health Surveill. In Press.

18. AstraZeneca UK Ltd. Fluenz tetra package leaflet. Available: https:// www.medicines.org.uk/emc/files/pil.3296.pdf [Accessed Aug 2018].

19. Gajewska M, Lewtak K, Scheres J, et al. Trends in hospitalization of children with bacterial pneumonia in Poland. Cent Eur J Public Health 2016;24:188-92.

20. European Center for Disease Prevention and Control (ECDC). Vaccine schedules in all countries of the European Union. Available: https://vaccine-schedule.ecdc.europa.eu/ [Accessed Aug 2018].

21. Clopper CJ, Pearson ES. The use of confidence or fiducial limits illustrated in the case of the binomial. Biometrika 1934;26:404-13.

22. Australian Bureau of Statistics. LiteracyStats: what is a standard error and relative standard error? reliability of estimates for labour 
force data. Available: http://www.abs.gov.au/websitedbs/d3310114. nsf/Home/What+is+a+Standard+Error+and+Relative+Standard+ Error,+Reliability+of+estimates+for+Labour+Force+data [Accessed Oct 2018].

23. Klein RJ, Proctor SE, Boudreault MA, et al. Healthy people 2010 criteria for data suppression. Healthy People 2010 Stat Notes 2002;24:1-12.

24. The International Conference on Harmonisation of Technical Requirements for Registration of Pharmaceuticals for Human Use (ICH). Medical Dictionary for Regulatory Activities - MedDRA. Available: https://www.meddra.org/basics [Accessed Aug 2018].

25. World Health Organization. International statistical classification of diseases and related health problems 10th revision (ICD-10). Available: http://apps.who.int/classifications/icd10/browse/2016/en [Accessed Sep 2018].
26. Clinical Data Interchange Standards Consortium (cdisc). Global regulatory requirements. Available: https://www.cdisc.org/resources/ global-regulatory-requirements [Accessed Jul 2019].

27. U.S. Food \& Drug Adminitration (FDA). Guidance for Industry. Oversight of Clinical Investigations - A Risk-Based Approach to Monitoring. Available: https://www.fda.gov/downloads/Drugs/ Guidances/UCM269919.pdf [Accessed Oct 2018]

28. European Medicines Agency. Guideline on good pharmacovigilance practices (GVP). module VI - collection, management and submission of reports of suspected adverse reactions to medicinal products (Rev 2). (EMA/873138/2011 Rev 2), 2017. Available: https:// www.ema.europa.eu/en/documents/regulatory-procedural-guideline/ guideline-good-pharmacovigilance-practices-gvp-module-vicollection-management-submission-reports_en.pdf [Accessed Jul 2019]. 